\title{
Improved Susceptibility Pattern of Antimicrobials Using Vital Energy Treatment on Shigella sonnei
}

\author{
Mahendra Kumar Trivedi ${ }^{1}$, Alice Branton ${ }^{1}$, Dahryn Trivedi ${ }^{1}$, Gopal Nayak $^{1}$, Mayank Gangwar ${ }^{2}$, \\ Snehasis Jana ${ }^{2, *}$ \\ ${ }^{1}$ Trivedi Global Inc., Henderson, NV, USA \\ ${ }^{2}$ Trivedi Science Research Laboratory Pvt. Ltd., Bhopal, Madhya Pradesh, India
}

Email address:

publication@trivedisrl.com (S. Jana)

\section{To cite this article:}

Mahendra Kumar Trivedi, Alice Branton, Dahryn Trivedi, Gopal Nayak, Mayank Gangwar, Snehasis Jana. Improved Susceptibility Pattern of Antimicrobials Using Vital Energy Treatment on Shigella sonnei. American Journal of Internal Medicine. Vol. 3, No. 6, 2015 , pp. $231-237$. doi: 10.11648/j.ajim.20150306.13

\begin{abstract}
Complementary and alternative medicine (CAM) has become increasingly popular and reported for countless benefits in biomedical health care systems. The study assessed the potential impact of The Trivedi Effect ${ }^{\circledR}$ (biofield energy) on Shigella sonnei for changes in antimicrobial sensitivity, biochemical study, and biotype number using MicroScan Walk-Away ${ }^{\circledR}$ system. The cells were obtained from MicroBioLogics Inc., USA bearing the American Type Culture Collection (ATCC 9290) number, and divided into two groups, Group (Gr.) I: control and Gr. II: treated. Gr. II was subjected to Mr. Trivedi's biofield energy treatment and further subdivided into two sub-groups, Gr. IIA and Gr. IIB. Gr. IIA was analyzed on day 10, while Gr. IIB was stored and analyzed on day 160 (Study I). The Gr. IIB sample was retreated on day 160 (Study II), and was divided into three separate tubes as first, second and third tube, which were analyzed on day 5, 10 and 15, respectively. Results showed that 35\% (7 out of 20) antimicrobials were reported with improved sensitivity profile. Moreover, the minimum inhibitory concentration study showed that $56.25 \%$ (18 out of 32) tested antimicrobials were reported with decreased concentration by two to four-fold as compared with the control after biofield treatment. The effect was further analyzed and sustained in the biochemical study, where $57.57 \%$ (19 out of 33) tested biochemicals showed altered reaction pattern as compared with the control. The biotype study showed an alteration in the biotype number in all the experimental treated groups as compared to the control. Encouraging results suggests that bioenergy healing treatment as an integrative medicine against $S$. sonnei would be a better and safe treatment approach in near future.
\end{abstract}

Keywords: Shigella sonnei, Bioenergy Healing, Shigellosis, Antibiogram, Biochemical Reaction, Biotype

\section{Introduction}

Shigella is a genus of Gram-negative, non-spore forming, non-motile, rod-shaped bacteria in close resemblance with Escherichia coli and Salmonella. Shigella sonnei (S. sonnei) is very fragile in experimental conditions and its natural habitat is human gastrointestinal tract [1]. Shigella causes dysentery known as shigellosis, it is endemic throughout the world and recognized as the major cause of childhood morbidity and mortality. S. sonnei is the major food-borne pathogen and generally transmitted through uncooked food or contaminated water. Data suggest that every year, approximately 165 million cases of Shigella infections and about 1.1 million Shigella-related deaths were reported [2]. It is naturally found in apes and humans, during an infection it causes bacillary dysentery. Shigella has limited access in a clean area and potable water, while effectively transmitted via fecal-oral route in areas with poor hygienic conditions [3]. A recent study reports the presence of Shigella DNA in up to a one-third population of the culture-negative samples [4].

Antimicrobial therapy is still the choice of treatment for shigellosis, however antimicrobials such as ampicillin, nalidixic acid, streptomycin, sulfamethoxazole-trimethoprim, and tetracycline showed strong resistance against Shigella, which is a major therapeutic challenge to prevent the infection [5]. One of the major mechanisms behind the emergence of multi-drug resistant Shigella spp. is its ability to acquire resistance factor (transmissible genes) from the environment or other bacteria [6]. However, this emergence of resistance isolates is due to the indiscriminate use of antibiotics. The 
preferred antibiotic against shigellosis is ciprofloxacin for both childhood and adult infections [7]. However, recent reports suggest that ciprofloxacin resistance isolates have been isolated in South Asian region, along with fluoroquinolone resistant Shigella dysenteriae type $1[8,9]$. Due to continuous resistance against newly developed or broad spectrum drug, authors have tried to evaluate the effect of integrative bioenergy medicine (The Trivedi Effect ${ }^{\circledR}$ ) and its potential benefits on $S$. sonnei.

Researchers are continuously exploring the potential of integrative medicine to promote the health and wellness across the world. The energy medicine is one of the major categories of complementary and alternative medicine (CAM) which includes either biofield therapies or bio-electromagnetic-based therapies. They are very popular in health care systems [10], and are classified under the subcategory of energy therapies by National Center for Complementary and Alternative Medicine (NCCAM) [11]. Biofield therapies include Qigong, Reiki, Yoga, Pranic healing and therapeutic touch that depend upon the state of mind, skills, and practice and are practiced worldwide [12-14]. NCCAM refers to the self-practice therapy as "mind-body medicine". The mind-body medicine or practice involves an alteration in the biomolecules conformation directly on molecular structure, or it may transfer bio-information via small energy signals [15]. Biofield treatment includes energy therapies that interact with patient's biofield and lead to improve people's health and wellbeing [16]. However, every cell in the human body can generate and receive different forms of energy viz. heat, light, sound, vibration, magnetism, and electricity. Epigenetics, biophysics, psychoneuroimmunology, metabolomics, bioengineering, biomedical imaging, proteomics, and frequency therapies are the emerging research areas in the field of bioenergy, as it is the fundamental of life. The biomolecules can absorb specific environmental frequencies, and responding into the useful way that is called biofield energy and the process is known as biofield treatment. Mr. Trivedi's unique biofield energy has been studied in the field of materials science research [17, 18], agricultural research $[19,20]$, and microbiology research [21, 22]. The biofield energy treatment as an integrative medicine acts as a complex communication system via a different range of electromagnetic frequencies, which carry messages from the environment to the organism and vice versa. Bioenergy treatment for microbial infections is an area that is often neglected by mainstream medicine research, and it must be considered as an important supplement to conventional antibiotic therapy. In continuation of the above significant outcomes of Mr. Trivedi's biofield energy treatment, and clinical importance of $S$. sonnei, the antibiogram, biochemical reactions, and biotyping were studied in biofield treated $S$. sonnei.

\section{Materials and Methods}

S. sonnei, American Type Culture Collection (ATCC 9290) strain was procured from MicroBioLogics, Inc., USA and stored in laboratory conditions for further use. Antimicrobials and biochemicals tested against control and treated S. sonnei were procured from Sigma-Aldrich (MA, USA). All the study parameters were evaluated using automated MicroScan Walk-Away ${ }^{\circledR}$ (Dade Behring Inc., West Sacramento, CA, USA) using Negative Breakpoint Combo 30 (NBPC 30) panel.

\subsection{Inoculum Preparation}

The turbidity standard technique using direct inoculation of revived and lyophilized strain of $S$. sonnei was used. Using a sterile wooden applicator stick or bacteriological loop, the surfaces of 4-5 large or 5-10 small morphologically similar cultures were touched for well-isolated colonies from an 18-24 hour non-inhibitory agar plate. Further, S. sonnei cells were emulsified in $3 \mathrm{~mL}$ of inoculum water to an equivalent of a $0.5 \mathrm{McF}$ arland barium sulfate turbidity standard. $100 \mu \mathrm{L}$ of the standardized suspension was pipetted into $25 \mathrm{~mL}$ of inoculum water using pluronic and inverted 8-10 times.

\subsection{Experimental Design}

The impact of biofield treatment on tested bacterium $S$. sonnei was evaluated in two groups.

Group I: The ATCC strain in the lyophilized state was considered as control. No treatment was given and analyzed for antimicrobial sensitivity, biochemical reactions and biotype number as per the standard protocol.

Group II: The lyophilized state sample of ATCC strain was divided into two parts named as Gr. IIA and Gr. IIB. Both the groups of ATCC strain of $S$. sonnei in lyophilized state were subjected to Mr. Trivedi's unique biofield treatment. Gr. IIA was analyzed on day 10 for antimicrobial sensitivity, biochemical reactions and biotype number as per the standard protocol, while Gr. IIB sample was stored in the lyophilized state for 160 days at $-70^{\circ} \mathrm{C}$. Gr. IIB was further sub-divided in two separate parts named as Gr. IIB - Study I and Gr. IIB - Study II.

Group IIB - Study I: After 160 days, the sample was revived and tested for antimicrobial sensitivity, MIC, biochemical reactions and biotyping as per the standard protocol.

Group IIB - Study II: The stored strain was revived from $-70^{\circ} \mathrm{C}$ and again provided Mr. Trivedi's biofield treatment (re-treatment) on day 160. After biofield retreatment, the sample was sub-cultured into three separate tubes on three different days (day 0, 5, and 10) and analyzed. Each sample was analyzed on 5 th day of its sub-culturing.

\subsection{Biofield Treatment Strategy}

The treated group samples of $S$. sonnei in lyophilized and revived state were subjected to Mr. Trivedi's biofield energy treatment. The treated group was handed over to Mr. Trivedi for biofield energy treatment under standard laboratory conditions. Mr. Trivedi provided the biofield treatment through his energy transmission process, which includes bioenergy emission to the samples without touching them. After treatment, the samples were returned in the same condition and stored at standard conditions as per the standard experimental protocol. The differences in parameters before and after the biofield treatment were noted and compared with control [23]. 


\subsection{Antimicrobial Susceptibility Test}

Investigation of antimicrobial susceptibility of $S$. sonnei was carried out with the help of automated instrument, MicroScan Walk-Away ${ }^{\circledR}$ using NBPC 30 panel. The selected panel was initially allowed to equilibrate to room temperature before rehydration, while panels were used on the same day. The experiments performed on MicroScan were miniaturized of the broth dilution antimicrobial susceptibility test that has been dehydrated. Briefly, $0.1 \mathrm{~mL}$ of the standardized suspension of $S$. sonnei was pipetted into $25 \mathrm{~mL}$ of inoculum water using pluronic, inverted 8 to 10 times followed by rehydration, and then incubation for approximately 16 hours at $35^{\circ} \mathrm{C}$. Rehydration and inoculation process were done with the help of RENOK $^{\circledR}$ system with inoculators-D (B1013-4). $25 \mathrm{~mL}$ of standardized inoculum suspension was poured into inoculum tray. The detailed antimicrobial sensitivity assay procedure and experimental conditions were followed as per manufacturer's instructions. The susceptibility pattern of antimicrobials (S: Susceptible, R: Resistant; and I: Intermediate) and MIC values were reported by observing the lowest antimicrobial concentration showing inhibition of growth [23].

\subsection{Biochemical Reaction Studies}

The biochemical reactions of $S$. sonnei were performed using the photometric or fluorogenic reader. On the basis of nature of bacilli (Gram-negative or Gram-positive), computerized reports were generated using conventional panels, which utilizes the photometric reader. Before commencing the experiment, the NBPC 30 panel was first incubated and read on the MicroScan Walkaway system. Further, the panel was removed from the system and recorded on the Biomic system within 1 hour. The instrument consisted of a database associated with collective information, which was required to identify the microbes with respect to group, genera, or species of the family. The detailed experimental procedure was followed as per manufacturer-recommended instructions [23].

\subsection{Identification of Organism by Biotype Number}

The biotype number of $S$. sonnei was determined on MicroScan Walk-Away ${ }^{\circledR}$ processed panel data report with the help of biochemical reactions data [23].

\section{Results and Discussion}

\subsection{Antimicrobial Susceptibility Test}

The impact of biofield treatment on $S$. sonnei for antimicrobial sensitivity result and MIC values of tested antimicrobials are summarized in Table 1 and 2, respectively. All the values presented are compared with respect to the control group (Gr. I). A total of twenty antimicrobials were selected for the sensitivity study, out of which six resistant antimicrobials against $S$. sonnei after treatment with bioenergy were reported with the improved sensitivity i.e. susceptible. Results showed that bioenergy treatment has a positive impact on resistant antimicrobials, while it did not hamper the sensitivity pattern of susceptible antimicrobials with constant effect during the experimental period. Antimicrobials such as ampicillin, aztreonam, cefotaxime, ceftazidime, chloramphenicol, and tetracycline were reported with improved sensitivity i.e. from resistance $(\mathrm{R})$ to susceptible $(\mathrm{S})$ in all the treated experimental groups. Similarly, cefepime was reported with slight improved sensitivity profile as intermediate (I) to susceptible (S) in all the treated experimental groups, as compared with the control. The susceptible pattern of rest of the tested antimicrobials remains constant throughout the study after biofield energy treatment. Overall, $35 \%$ of the tested antimicrobials results in improved sensitivity profile after biofield treated on $S$. sonnei.

MIC results of tested antimicrobials against control and biofield treated S. sonnei are presented in Table 2. The total of thirty-two antimicrobials were selected for MIC calculation after biofield energy treatment. The results showed that 18 out of 32 tested antimicrobials $(56.25 \%)$ were reported with an improved MIC values (two to four-fold decrease) after biofield treatment as compared with the control values. The maximum of four-fold decrease in MIC value was reported in case of cefotaxime ( $>32$ to $\leq 8 \mu \mathrm{g} / \mathrm{mL}$ ) and cefuroxime ( $>16$ to $\leq 4 \mu \mathrm{g} / \mathrm{mL}$ ) in all the experimental treated group as compared with the control. Cefotetan also reported with two-fold improved MIC value i.e. $>32$ to $\leq 16 \mu \mathrm{g} / \mathrm{mL}$ except in Gr. IIB, Study I, on day $160(32 \mu \mathrm{g} / \mathrm{mL})$ as compared to the control. However, two-fold decrease in MIC values i.e. $>16$ to $\leq 8$ $\mu \mathrm{g} / \mathrm{mL}$ were reported in case of antimicrobials such as ampicillin, aztreonam, cefoxitin, ceftazidime, and chloramphenicol in all the treated groups. Cefazolin and cefepime were reported with an improved MIC values i.e. 16 to $\leq 8 \mu \mathrm{g} / \mathrm{mL}$ as compared with the control in all the treated experimental groups. Moreover, gentamicin, tetracycline, and tobramycin were reported with two-fold decrease in MIC value ( $>8$ to $\leq 4 \mu \mathrm{g} / \mathrm{mL}$ ) as compared to the control in all the biofield treated groups. The two-fold decrease was also reported in amikacin $(>32$ to $\leq 16 \mu \mathrm{g} / \mathrm{mL})$ and nitrofurantoin ( $>64$ to $\leq 32 \mu \mathrm{g} / \mathrm{mL}$ ) in all the treated experimental groups, while cephalothin (16 to $\leq 8 \mu \mathrm{g} / \mathrm{mL}$ ) also showed similar improved MIC values except in Gr IIB, Study II, on day 15. Extended-spectrum $\beta$-lactamases (ESBL-b and b Scrn) were reported with slight decrease in the MIC values of all the treated groups as compared with the control. The rest of the antimicrobials did not report any alteration in MIC values as compared with the control.

Shigella species and its associated infections remain an important public health issue, especially in developing countries. In the United States, 10,000 to 15,000 cases of shigellosis are reported each year in both children and adults. Reports suggest that from 2004 onwards, increased resistance among Shigella isolates against first-line antimicrobials such as ampicillin and trimethoprim-sulfamethoxazole were incidence in children younger than 5 years of age [24]. Resistance of Shigella species to ampicillin, sulfonamides, and tetracyclines, has been reported worldwide, hence there uses as empirical therapy is not recommended. Due to increased resistance of third-generation cephalosporins such 
as ceftriaxone, and cefixime, fluoroquinolones, azithromycin as alternative antibiotics are suggested for the treatment of

Shigella species infections in children [25].

Table 1. Effect of biofield treatment on antimicrobial susceptibility pattern of tested antimicrobials against Shigella sonnei.

\begin{tabular}{|c|c|c|c|c|c|c|c|}
\hline \multirow{2}{*}{ S. No. } & \multirow{2}{*}{ Antimicrobial } & \multirow{2}{*}{$\begin{array}{l}\text { Gr. I } \\
\text { Control }\end{array}$} & \multirow{2}{*}{$\begin{array}{l}\text { Gr. IIA } \\
\text { Day } 10\end{array}$} & \multirow{2}{*}{$\begin{array}{l}\text { Gr. IIB, Study I } \\
\text { Day } 160\end{array}$} & \multicolumn{3}{|c|}{ Gr. IIB, Study II } \\
\hline & & & & & Day +5 & Day +10 & Day +15 \\
\hline 1. & Amoxicillin/k-clavulanate & $\mathrm{S}$ & $\mathrm{S}$ & $\mathrm{S}$ & $\mathrm{S}$ & $\mathrm{S}$ & $\mathrm{S}$ \\
\hline 2. & Ampicillin/sulbactam & S & S & $\mathrm{S}$ & S & S & $\mathrm{S}$ \\
\hline 3. & Ampicillin & $\mathrm{R}$ & S & $\mathrm{S}$ & S & S & $\mathrm{S}$ \\
\hline 4. & Aztreonam & $\mathrm{R}$ & $\mathrm{S}$ & $\mathrm{S}$ & S & $\mathrm{S}$ & $\mathrm{S}$ \\
\hline 5. & Cefepime & I & $\mathrm{S}$ & $\mathrm{S}$ & $\mathrm{S}$ & $\mathrm{S}$ & $\mathrm{S}$ \\
\hline 6. & Cefotaxime & $\mathrm{R}$ & S & $\mathrm{S}$ & S & S & S \\
\hline 7. & Ceftazidime & $\mathrm{R}$ & $\mathrm{S}$ & $\mathrm{S}$ & S & $\mathrm{S}$ & $\mathrm{S}$ \\
\hline 8. & Ceftriaxone & S & $\mathrm{S}$ & $\mathrm{S}$ & $\mathrm{S}$ & $\mathrm{S}$ & S \\
\hline 9. & Chloramphenicol & $\mathrm{R}$ & $\mathrm{S}$ & $\mathrm{S}$ & S & S & $\mathrm{S}$ \\
\hline 10. & Ciprofloxacin & S & $\mathrm{S}$ & $\mathrm{S}$ & $\mathrm{S}$ & S & S \\
\hline 11. & Gatifloxacin & $\mathrm{S}$ & $\mathrm{S}$ & $\mathrm{S}$ & $\mathrm{S}$ & $\mathrm{S}$ & $\mathrm{S}$ \\
\hline 12. & Imipenem & S & $\mathrm{S}$ & $\mathrm{S}$ & $\mathrm{S}$ & S & $\mathrm{S}$ \\
\hline 13. & Levofloxacin & S & S & $\mathrm{S}$ & S & S & $\mathrm{S}$ \\
\hline 14. & Meropenem & $\mathrm{S}$ & $\mathrm{S}$ & $\mathrm{S}$ & $\mathrm{S}$ & $\mathrm{S}$ & $\mathrm{S}$ \\
\hline 15. & Moxifloxacin & S & $\mathrm{S}$ & $\mathrm{S}$ & $\mathrm{S}$ & S & S \\
\hline 16. & Piperacillin/tazobactam & $\mathrm{S}$ & $\mathrm{S}$ & $\mathrm{S}$ & $\mathrm{S}$ & $\mathrm{S}$ & $\mathrm{S}$ \\
\hline 17. & Piperacillin & $\mathrm{S}$ & $\mathrm{S}$ & $\mathrm{S}$ & $\mathrm{S}$ & $\mathrm{S}$ & $\mathrm{S}$ \\
\hline 18. & Tetracycline & $\mathrm{R}$ & $\mathrm{S}$ & $\mathrm{S}$ & S & S & $\mathrm{S}$ \\
\hline 19. & Ticarcillin/k-clavulanate & $\mathrm{S}$ & $\mathrm{S}$ & $\mathrm{s}$ & $\mathrm{S}$ & $\mathrm{S}$ & $\mathrm{S}$ \\
\hline 20. & Trimethoprim/Sulfamethoxazole & S & S & $\mathrm{S}$ & S & S & S \\
\hline
\end{tabular}

R: Resistant; I: Intermediate; S: Susceptible; Gr: Group

Table 2. Minimum inhibitory concentration (MIC) of tested antimicrobials against biofield energy treated Shigella sonnei.

\begin{tabular}{|c|c|c|c|c|c|c|c|}
\hline \multirow{2}{*}{ S. No. } & \multirow{2}{*}{ Antimicrobial } & \multirow{2}{*}{$\begin{array}{l}\text { Gr. I } \\
\text { Control }\end{array}$} & \multirow{2}{*}{$\begin{array}{l}\text { Gr. IIA } \\
\text { Day } 10\end{array}$} & \multirow{2}{*}{$\begin{array}{l}\text { Gr. IIB, Study I } \\
\text { Day } 160\end{array}$} & \multicolumn{3}{|c|}{ Gr. IIB, Study II } \\
\hline & & & & & Day +5 & Day +10 & Day +15 \\
\hline 1. & Amikacin & $>32$ & $\leq 16$ & $\leq 16$ & $\leq 16$ & $\leq 16$ & $\leq 16$ \\
\hline 2. & Amoxicillin/k-clavulanate & $\leq 8 / 4$ & $\leq 8 / 4$ & $\leq 8 / 4$ & $\leq 8 / 4$ & $\leq 8 / 4$ & $\leq 8 / 4$ \\
\hline 3. & Ampicillin/sulbactam & $\leq 8 / 4$ & $\leq 8 / 4$ & $\leq 8 / 4$ & $\leq 8 / 4$ & $\leq 8 / 4$ & $\leq 8 / 4$ \\
\hline 4. & Ampicillin & $>16$ & $\leq 8$ & $\leq 8$ & $\leq 8$ & $\leq 8$ & $\leq 8$ \\
\hline 5. & Aztreonam & $>16$ & $\leq 8$ & $\leq 8$ & $\leq 8$ & $\leq 8$ & $\leq 8$ \\
\hline 6. & Cefazolin & 16 & $\leq 8$ & $\leq 8$ & $\leq 8$ & $\leq 8$ & $\leq 8$ \\
\hline 7. & Cefepime & 16 & $\leq 8$ & $\leq 8$ & $\leq 8$ & $\leq 8$ & $\leq 8$ \\
\hline 8. & Cefotaxime & $>32$ & $\leq 8$ & $\leq 8$ & $\leq 8$ & $\leq 8$ & $\leq 8$ \\
\hline 9. & Cefotetan & $>32$ & $\leq 16$ & 32 & $\leq 16$ & $\leq 16$ & $\leq 16$ \\
\hline 10. & Cefoxitin & $>16$ & $\leq 8$ & $\leq 8$ & $\leq 8$ & $\leq 8$ & $\leq 8$ \\
\hline 11. & Ceftazidime & $>16$ & $\leq 8$ & $\leq 8$ & $\leq 8$ & $\leq 8$ & $\leq 8$ \\
\hline 12. & Ceftriaxone & $\leq 8$ & $\leq 8$ & $\leq 8$ & $\leq 8$ & $\leq 8$ & $\leq 8$ \\
\hline 13. & Cefuroxime & $>16$ & $\leq 4$ & $\leq 4$ & $\leq 4$ & $\leq 4$ & $\leq 4$ \\
\hline 14. & Cephalothin & 16 & $\leq 8$ & $\leq 8$ & $\leq 8$ & $\leq 8$ & 16 \\
\hline 16. & Ciprofloxacin & $\leq 1$ & $\leq 1$ & $\leq 1$ & $\leq 1$ & $\leq 1$ & $\leq 1$ \\
\hline 17. & ESBL-a Scrn & $>4$ & $\leq 4$ & $\leq 4$ & $\leq 4$ & $\leq 4$ & $\leq 4$ \\
\hline 18. & ESBL-b Scrn & $>1$ & $\leq 1$ & $\leq 1$ & $\leq 1$ & $\leq 1$ & $\leq 1$ \\
\hline 19. & Gatifloxacin & $\leq 2$ & $\leq 2$ & $\leq 2$ & $\leq 2$ & $\leq 2$ & $\leq 2$ \\
\hline 20. & Gentamicin & $>8$ & $\leq 4$ & $\leq 4$ & $\leq 4$ & $\leq 4$ & $\leq 4$ \\
\hline 21. & Imipenem & $\leq 4$ & $\leq 4$ & $\leq 4$ & $\leq 4$ & $\leq 4$ & $\leq 4$ \\
\hline 22. & Levofloxacin & $\leq 2$ & $\leq 2$ & $\leq 2$ & $\leq 2$ & $\leq 2$ & $\leq 2$ \\
\hline 23. & Meropenem & $\leq 4$ & $\leq 4$ & $\leq 4$ & $\leq 4$ & $\leq 4$ & $\leq 4$ \\
\hline 24. & Moxifloxacin & $\leq 2$ & $\leq 2$ & $\leq 2$ & $\leq 2$ & $\leq 2$ & $\leq 2$ \\
\hline 25. & Nitrofurantoin & $>64$ & $\leq 32$ & $\leq 32$ & $\leq 32$ & $\leq 32$ & $\leq 32$ \\
\hline 26. & Norfloxacin & $\leq 4$ & $\leq 4$ & $\leq 4$ & $\leq 4$ & $\leq 4$ & $\leq 4$ \\
\hline 27. & Piperacillin/tazobactam & $\leq 16$ & $\leq 16$ & $\leq 16$ & $\leq 16$ & $\leq 16$ & $\leq 16$ \\
\hline 28. & Piperacillin & $\leq 16$ & $\leq 16$ & $\leq 16$ & $\leq 16$ & $\leq 16$ & $\leq 16$ \\
\hline 29. & Tetracycline & $>8$ & $\leq 4$ & $\leq 4$ & $\leq 4$ & $\leq 4$ & $\leq 4$ \\
\hline 30. & Ticarcillin/k-clavulanate & $\leq 16$ & $\leq 16$ & $\leq 16$ & $\leq 16$ & $\leq 16$ & $\leq 16$ \\
\hline
\end{tabular}


MIC values are presented in $\mu \mathrm{g} / \mathrm{mL}$; Gr.: Group; ESBL-a, b Scrn: Extended spectrum beta-lactamase a, b Screen

Biofield energy treatment on $S$. sonnei significantly improved the sensitivity profile of most of the antibiotics. Cefotaxime and cefuroxime were reported with four-fold decreased in MIC values, while two-fold decreased was also reported in ampicillin, aztreonam, cefepime, ceftazidime, chloramphenicol, and tetracycline along with improved susceptibility as compared with the control. A study reports that single-dose tetracycline therapy for shigellosis in adults showed very effective results [26]. According to Rubik et al., the impact of bioenergy (Reiki treatment) showed an influence on the in-vitro growth of bacteria cultures [27]. Our experimental results suggest that biofield energy treatment (The Trivedi Effect ${ }^{\circledR}$ ) was significantly decreased the MIC of tested antimicrobials by two to four fold with improved sensitivity from resistance to susceptible; hence, it could be used as an alternate treatment approach as CAM against shigellosis in adults as well as in children in the near future. The treatment on $S$. sonnei might alter the ligand-receptor protein interactions of antibiotic that results in altered phenotypic characteristics [28].

\subsection{Biochemical Reactions Studies}

Table 3. Effect of biofield treatment on biochemical reactions of Shigella sonnei.

\begin{tabular}{|c|c|c|c|c|c|c|c|c|}
\hline \multirow{3}{*}{ S. No. } & \multirow{3}{*}{ Code } & \multirow{3}{*}{ Biochemical } & \multicolumn{6}{|c|}{ Type of Response } \\
\hline & & & \multirow{2}{*}{$\begin{array}{l}\text { Gr. I } \\
\text { Control } \\
\end{array}$} & \multirow{2}{*}{\begin{tabular}{|l} 
Gr. IIA \\
Day 10 \\
\end{tabular}} & \multirow{2}{*}{$\begin{array}{l}\text { Gr. IIB, Study I } \\
\text { Day } 160\end{array}$} & \multicolumn{3}{|c|}{ Gr. IIB, Study II } \\
\hline & & & & & & Day +5 & Day +10 & Day +15 \\
\hline 1. & $\mathrm{ACE}$ & Acetamide & - & - & - & - & - & - \\
\hline 2. & $\mathrm{ADO}$ & Adonitol & + & - & - & - & - & - \\
\hline 3. & ARA & Arabinose & + & + & + & + & + & + \\
\hline 4. & $\mathrm{ARG}$ & Arginine & + & - & - & - & - & - \\
\hline 5. & CET & Cetrimide & - & - & - & - & - & - \\
\hline 6. & $\mathrm{CF} 8$ & Cephalothin & + & - & - & - & - & + \\
\hline 7. & CIT & Citrate & + & - & - & - & - & - \\
\hline 8. & CL4 & Colistin & + & - & - & - & - & - \\
\hline 9. & $\mathrm{ESC}$ & Esculin hydrolysis & + & - & - & - & - & - \\
\hline 10. & FD64 & Nitrofurantoin & + & - & - & - & - & - \\
\hline 11. & GLU & Glucose & + & + & + & + & + & + \\
\hline 12. & $\mathrm{H}_{2} \mathrm{~S}$ & Hydrogen sulfide & + & - & - & - & - & - \\
\hline 13. & IND & Indole & - & - & - & - & - & - \\
\hline 14. & INO & Inositol & - & - & - & - & - & - \\
\hline 15. & K4 & Kanamycin & + & - & - & + & + & + \\
\hline 16. & LYS & Lysine & + & - & - & - & - & - \\
\hline 17. & MAL & Malonate & + & - & - & - & - & - \\
\hline 18. & MEL & Melibiose & + & - & - & - & - & - \\
\hline 19. & NIT & Nitrate & + & + & + & + & + & + \\
\hline 20. & $\mathrm{OF} / \mathrm{G}$ & Oxidation-fermentation/glucose & + & + & + & + & + & + \\
\hline 21. & ONPG & Galactosidase & + & + & + & + & + & + \\
\hline 22. & ORN & Ornithine & + & + & + & + & + & + \\
\hline 23. & OXI & Oxidase & - & - & - & - & - & - \\
\hline 24. & $\mathrm{P} 4$ & Penicillin & + & + & + & + & + & + \\
\hline 25. & RAF & Raffinose & + & - & - & - & - & - \\
\hline 26. & RHA & Rhamnose & + & + & + & + & + & + \\
\hline 27. & SOR & Sorbitol & + & - & - & - & - & - \\
\hline 28. & SUC & Sucrose & + & - & - & - & - & - \\
\hline 29. & TAR & Tartrate & + & - & - & - & - & - \\
\hline 30. & TDA & Tryptophan deaminase & - & - & - & - & - & - \\
\hline 31. & TO4 & Tobramycin & + & - & - & - & - & - \\
\hline 32. & URE & Urea & + & - & - & - & - & - \\
\hline 33. & VP & Voges-Proskauer & + & - & - & - & - & - \\
\hline
\end{tabular}

-: negative; +: positive; Gr.: Group

The results obtained from different sets of biochemical reactions studies of $S$. sonnei are summarized in Table 3. The biochemical reactions showed negative reaction i.e. $(+)$ positive to (-) negative in 19 out of 33 tested biochemical namely, adonitol, arginine, citrate, colistin, esculin hydrolysis, nitrofurantoin, hydrogen sulfide, lysine, malonate, melibiose, raffinose, sorbitol, sucrose, tartrate, tobramycin, urea, and Voges-Proskauer. Cephalothin also showed the similar negative reaction in all the experimentally treated groups except in Gr. IIB, Study II, on day 15 as compared to the control. Kanamycin was reported with a negative reaction after biofield treatment in the lyophilized state in Gr. IIA, on 
day 10 and Gr. IIB, Study I, on day 160, while again reported with positive reaction i.e. (-) negative to $(+)$ positive after re-treatment in Gr. IIB, Study II, on day 5, 10, and 15 . The rest of the tested biochemicals did not show any alteration in a biochemical reaction with respect to the control. Overall, 19 out of 33 tested biochemicals $(57.57 \%)$ were reported for altered biochemical reactions pattern as compared to the control. The biochemical reactions of $S$. sonnei determine the presence of various enzyme which were used in identifying the microorganisms. Rapid identification can be accomplished with specific set of biochemical test, which is the most common approach for determining the genus and species of an organism. This will define the ability of a microorganism to grow and survive in the presence of certain inhibitors used in various biochemical reactions [29].

\subsection{Identification of Organism by Biotype Number}

The effect of biofield treatment was further analyzed on $S$. sonnei for biotype number identification based on the database associated with collective information of conventional biochemical characters. In this experiment, biotyping was performed using an automated system, and the results showed a change in biotype number (4300 1010) in Gr. IIA (on day 10), Gr. IIB (Study I, on day 160), Gr. IIB (Study II, on day 5 and 10) as compared to the control Gr. I (7736 7376). Gr. IIB, Study II was also reported for altered biotype number as 4300 1012, on day 15 as compared to the control (Table 4). However, species alteration was not reported in any of the experimental treated groups after biofield energy treatment as compared to the control. This change of biotype number may be due to the alteration of some enzymatic reactions after the biofield energy treatment.

Table 4. Effect of biofield treatment on biotype number of Shigella sonnei.

\begin{tabular}{|c|c|c|c|c|c|c|}
\hline \multirow{2}{*}{ Feature } & \multirow{2}{*}{$\begin{array}{l}\text { Gr. I } \\
\text { Control }\end{array}$} & \multirow{2}{*}{$\begin{array}{l}\text { Gr. IIA } \\
\text { Day } 10\end{array}$} & \multirow{2}{*}{$\begin{array}{l}\text { Gr. IIB, Study I } \\
\text { Day } 160\end{array}$} & \multicolumn{3}{|c|}{ Gr. IIB, Study II } \\
\hline & & & & Day +5 & Day +10 & Day +15 \\
\hline Biotype number & 77367376 (Very rare biotype) & 43001010 & 43001010 & 43001010 & 43001010 & 43001012 \\
\hline Organism identification & S. sonnei & S. sonnei & S. sonnei & S. sonnei & S. sonnei & S. sonnei \\
\hline
\end{tabular}

\section{Conclusions}

Biofield energy treatment on $S$. sonnei results in an improved antimicrobial sensitivity in $35 \%$ tested antimicrobials, while decreased MIC values by two-four fold were reported in $56.25 \%$ tested antimicrobials as compared to the control. The increased sensitivity pattern and an improved MIC values after biofield treatment on $S$. sonnei suggest the alterations at enzyme/genetic level due to the impact of external energy. Further, the biofield effect was reported on characteristic biochemical reactions of $S$. sonnei, as 19 out of 33 tested biochemical reactions were altered with respect to the control. On the basis of biochemical reaction pattern, biotyping results showed an alteration in the biotype numbers in all the experimental treated groups with respect to the control. Overall, after considering significant effects of bioenergy healing, and benefits of therapies in different research areas, it can be concluded that Mr. Trivedi's unique biofield energy treatment could be applied to improve the antimicrobials sensitivity pattern.

\section{Abbreviations}

NCCAM: National Center for Complementary and Alternative Medicine;

CAM: Complementary and Alternative Medicine;

ATCC: American Type Culture Collection;

NBPC 30: Negative Breakpoint Combo 30;

MIC: Minimum Inhibitory Concentration

\section{Acknowledgements}

The authors gratefully acknowledged the support of Trivedi science, Trivedi testimonials and Trivedi master wellness and the whole team of PD Hinduja National Hospital and MRC, Mumbai, Microbiology Lab for their experimental support.

\section{References}

[1] Yang F, Yang J, Zhang X, Chen L, Jiang Y, et al. (2005) Genome dynamics and diversity of Shigella species, the etiologic agents of bacillary dysentery. Nucleic Acids Res 33: 6445-6458.

[2] Kotloff KL, Winickoff JP, Ivanoff B, Clemens JD, Swerdlow DL, et al. (1999) Global burden of Shigella infections: implications for vaccine development and implementation of control strategies. Bull World Health Organ 77: 651-666.

[3] Weissman JB, Gangorosa EJ, Schmerler A, Marier RL, Lewis JN (1975) Shigellosis in day-care centres. Lancet 1: 88-90.

[4] Von Seidlein L, Kim DR, Ali M, Lee H, Wang X, et al. (2006) A multicentre study of Shigella diarrhoea in six Asian countries: Disease burden, clinical manifestations and microbiology. PLoS Med 3: e353.

[5] Dutta S, Rajendran K, Roy S, Chatterjee A, Dutta P, et al. (2002) Shifting serotypes, plasmid profile analysis and antimicrobial resistance pattern of Shigellae strains isolated from Kolkata, India during 1995-2000. Epidemiol Infect 129: 235-243.

[6] Sack RB, Rahman M, Yunus M, Khan EH (1997) Antimicrobial resistance in organisms causing diarrheal disease. Clin Infect Dis 24: S102-S105.

[7] Salam MA, Dhar U, Khan WA, Bennish ML (1998) Randomised comparison of ciprofloxacin suspension and pivmecillinam for childhood shigellosis. Lancet 352: 522-527.

[8] Talukder KA, Khajanchi BK, Islam MA, Dutta DK, Islam Z, et al. (2004) Genetic relatedness of ciprofloxacin resistant Shigella dysenteriae Type 1 strains isolated in south Asia. J Antimicrob Chemother 54: 730-734. 
[9] Talukder KA, Khajanchi BK, Islam MA, Islam Z, Dutta DK, et al. (2006) Fluoroquinolone resistance linked to both gyrA and parC mutations in the quinolone resistance-determining region of Shigella dysenteriae Type 1. Curr Microbiol 52: 108-111.

[10] Koithan M (2009) Introducing complementary and alternative therapies. J Nurse Pract 5: 18-20.

[11] NIH, National Center for Complementary and Alternative Medicine. CAM Basics. Publication 347. [October 2, 2008]. Available at: http://nccam.nih.gov/health/whatiscam/

[12] Movaffaghi Z, Hassanpoor M, Farsi M, Hooshmand $P$, Abrishami F (2006) Effects of therapeutic touch on blood hemoglobin and hematocrit level. J Holist Nurs 24: 41-48.

[13] Olson M, Sneed N, Lavia M, Virella G, Bonadonna R, et al. (1997) Stress-induced immunosuppression and therapeutic touch. Altern Ther Health Med 3: 68-74.

[14] Wirth DP (1990) The effect of none contact therapeutic touch on the healing rate of full thickness dermal wounds. Subtle Energies 1: 1-20.

[15] Schwartz GE, Simon WL, Carmona R (2007) The energy healing experiments: Science reveals our natural power to heal. (1stedn), Atria Books.

[16] Movaffaghi Z, Farsi M (2009) Biofield therapies: Biophysical basis and biological regulations? Complement Ther Clin Pract 15: $35-37,31$.

[17] Trivedi MK, Nayak G, Patil S, Tallapragada RM, Latiyal O (2015) Studies of the atomic and crystalline characteristics of ceramic oxide nano powders after bio field treatment. Ind Eng Manage 4: 161 .

[18] Trivedi MK, Patil S, Nayak G, Jana S, Latiyal O (2015) Influence of biofield treatment on physical, structural and spectral properties of boron nitride. J Material Sci Eng 4: 181.

[19] Trivedi MK, Nayak G, Patil S, Tallapragada RM, Latiyal O (2015) Studies of the atomic and crystalline characteristics of ceramic oxide nano powders after bio field treatment. Ind Eng Manage 4: 161.
[20] Trivedi MK, Patil S, Nayak G, Jana S, Latiyal O (2015) Influence of biofield treatment on physical, structural and spectral properties of boron nitride. J Material Sci Eng 4: 181.

[21] Trivedi MK, Patil S, Harish S, Gangwar M, Jana S (2015) Biofield treatment: An alternative approach to combat multidrug-resistant susceptibility pattern of Raoultella ornithinolytica. Altern Integr Med 4: 193.

[22] Trivedi MK, Patil S, Shettigar H, Bairwa K, Jana S (2015) Phenotypic and biotypic characterization of Klebsiella oxytoca: An impact of biofield treatment. J Microb Biochem Technol 7: 203-206.

[23] Fader RC, Weaver E, Fossett R, Toyras M, Vanderlaan J, et al. (2013) Multilaboratory study of the biomic automated well-reading instrument versus MicroScan WalkAway for reading MicroScan antimicrobial susceptibility and identification panels. J Clin Microbiol 51: 1548-1554.

[24] Niyogi SK (2005) Shigellosis. J Microbiol 43: 133-143.

[25] Ben JK Tan (1995) Cefixime use in children: When and why. Can J Infect Dis 6: 204-205.

[26] Pickering LK, DuPont HL, Olarte J (1978) Single-dose tetracycline therapy for shigellosis in adults. JAMA 239: 853-854.

[27] Rubik B, Brooks AJ, Schwartz GE (2006) In vitro effect of Reiki treatment on bacterial cultures: Role of experimental context and practitioner well-being. J Altern Complement Med 12: 7-13.

[28] Hintz KJ, Yount GL, Kadar I, Schwartz G, Hammerschlag R, et al. (2003) Bioenergy definitions and research guidelines. Altern Ther Health Med 9: A13-A30.

[29] MacFaddin JF (2000) Biochemical tests for identification of medical bacteria. (3rdedn), Lippincott Williams \& Wilkins, Philadelphia, PA. 